Esta revista forma parte del acervo de la Biblioteca Jurídica Virtual del Instituto de Investigaciones Jurídicas de la UNAM

BRemer, Juan José, Tiempos de guerra y paz. Los pilares de la democracia: de Westfalia a San Francisco, Debolsillo, 2017, 292 pp.

Saludo al libro de Juan José Bremer en su tercera edición, Tiempos de guerra y paz. Los pilares de la diplomacia, deWestfalia a San Francisco, publicado por la editorial Debolsillo. El autor emprende un viaje retrospectivo, comprendiendo también al Congreso de Viena de 1814-1815 y a la Paz de Versalles de 1919, por los cuatro momentos de la Europa moderna, como los llama el autor, que se engarzan por medio de una continuidad sobresaltada y de rupturas provocadas por los intereses contrapuestos de las grandes potencias.

La obra es fruto de muchos años de estudio e investigación acuciosa, vivificada por la experiencia del autor al haber servido como embajador de México en sitios donde tuvieron lugar los acontecimientos históricos que lo ocupan: Alemania, Suecia, Rusia, España, Estados Unidos y Gran Bretaña. Tuvo la oportunidad de pulsar directamente los lugares de las batallas, de dialogar con expertos sobre los temas, de asistir a los museos y de acceder a archivos y a colecciones cartográficas. La erudita exposición es sustentada por citas a pie de página, cuadros particulares que amplían puntos biográficos de los personajes o relatos de lugares, todo un festín de proporciones enciclopédicas. Ortega y Gasset decía que una obra es vida humana objetivada, producto de la inteligencia, de la sensibilidad, de la plenitud que en ella se plasma. La aseveración del ilustre filósofo español se cumple a cabalidad en el presente libro, es al propio autor al que reconocemos en sus páginas.

El tratamiento de las épocas que realiza Bremer trasciende la política de los gobiernos, la habilidad y la visión de los diplomáticos y estadistas. Al suceder histórico lo condicionan el avance de los conocimientos científicos y la aventura del pensamiento, siembra de los nuevos modos de organización para la convivencia, dentro de los países y entre ellos. De ahí el valor de la narrativa de Bremer al pintar la atmósfera cultural de esos tiempos. 
Esta revista forma parte del acervo de la Biblioteca Jurídica Virtual del Instituto de Investigaciones Jurídicas de la UNAM

En el entorno que envolvió al Congreso de Westfalia (1644-1648) y los tratados resultantes de Münster y Osnabrück influyeron la revolución científica de Copérnico, quien en su obra Las revoluciones de las esferas celestes de 1543, establecía que no era el Sol ni el sistema solar conocido, ni las estrellas a la vista los que giraban alrededor de la Tierra, sino ésta la que orbitaba en torno al astro rey. Apenas había transcurrido siglo y medio del descubrimiento del continente que terminó llamándose América y la circunvalación que probó la redondez de nuestro hábitat planetario. Nació con estas hazañas nuestra idea del mundo, como lo diagnosticó José Gaos.

Bremer asienta que las transformaciones de la visión sobre nuestra propia realidad física influyeron en una revisión del papel del ser humano y de los pueblos en la sociedad y en una fundamentación desafiante del poder de las monarquías. De pronto, los reyes ya no podían estar seguros en la comodidad de los tronos, y en ese sentido recuerda la ejecución de Carlos I en Inglaterra. Otro afluente de los replanteamientos societarios fue el cisma religioso del cristianismo que se escindió en tres ramas: católica, protestante y el calvinista, originando convulsiones internas, sangrientas y fanatizadas y un reajuste de la estructura internacional. Las exigencias pluralistas pusieron contra la pared a las concepciones monolíticas del alma y de la realidad circundante.

Bremer pasa revista a los pensadores. Maquiavelo concibe una nueva formación política: el Estado; en tanto, Jean Bodin, por encima del soberano, funda la noción de la soberanía, elemento de cohesión interna de los países y de individualización de los mismos con respecto al exterior. No en balde, entonces, uno de los puntales del nuevo orden pactado en Westfalia en 1648 fue el debilitamiento del Sacro Imperio Romano Germánico (que sobreviviría hasta 1808) de cara a los principados alemanes y de los otros países, así como la disminución de la preponderancia del Papado en los asuntos terrenales. Fue postulada la igualdad de credos religiosos y su tolerancia, ideadas únicamente para los principados alemanes. Triunfadores de los arreglos, emergieron Francia y Suecia. De significación substancial fueron los principios emanantes de Westfalia: la igualdad entre los Estados, la integridad territorial vigente entre ellos y el principio de la no intervención, normas reguladoras todavía de la sociedad contemporánea, inmersa en la avalancha de factores que dibujan una modernidad deslumbrante y contradictoria. Ello ha hecho sostener a Bremer la prevalencia hasta nuestros días de una sociedad post-Westfalia (libro publicado por el 
Esta revista forma parte del acervo de la Biblioteca Jurídica Virtual del Instituto de Investigaciones Jurídicas de la UNAM

Instituto de Investigaciones Jurídicas, De Westfalia a Post-Wesfalia. Hacia un nuevo orden internacional), coincidente con la inquietud de una legión de doctrinantes y iusinternacionalistas en la búsqueda de un nuevo modelo explicativo de la sociedad y del derecho internacional del presente. $\mathrm{Cu}$ riosamente, Angel J. Rodrigo, de la Universidad Pompeu Fabra, habla de la sociedad "Worldfalia".

En 1814 y 1815 , el Congreso deViena fue convocado para sepultar la era bonapartista. Bremer, sostiene, sin embargo, que el pretendido nuevo orden de principios del siglo XIX, fundado por las monarquías triunfadoras, no podía acabar con el germen ideológico de la Revolución Francesa y de la Revolución norteamericana de Independencia que apostaron por la fundamentación del poder político en el basamento de las colectividades y no en la cúspide monárquica de la pirámide social. La frase pretenciosa de Luis XIV “L'Etat c' est moi” sufrió un vuelco fenomenal para darle protagonismo a las multitudes en el quehacer público: "L'Etat c' est nous" (Schwarsenberger, George, La política del poder). El Congreso de Viena se esmeró tanto en apuntalar el principio de la legitimidad dinástica como en darle rienda suelta a la rapiña territorial.

Merece subrayarse, en lo positivo del Congreso de Viena, la adopción de la Declaración contra el Tráfico de Esclavos propuesta por la Gran Bretaña, limitada en sus alcances, pues Bremer aclara que no fue contra la esclavitud, mérito que, en sus palabras, corresponde a Miguel Hidalgo con su proclama de abolición de la esclavitud de 1810. Los vencedores colocaron en el trono de Francia a Luis XVIII, hermano del guillotinado veinte años antes, y restauraron la dinastía de los Borbones. Napoleón, se había ganado a pulso su jubilación en la isla de Santa Elena. Pero ojo, los triunfos espectaculares suelen fincarse en arenas movedizas. Lo diagnostica el autor, los acuerdos parecían un ropaje que le quedaba ajustado al incipiente siglo XIX: la Revolución Industrial, movimientos culturales emergentes como el Romanticismo, el nacionalismo, el liberalismo y el socialismo. Un coctel provocativo que golpeaba los cimientos ilusionados del nuevo orden. A la par, en el Congreso de Viena despuntaron las tendencias a la unificación de los principados alemanes que abriría el paso a la constitución del imperio alemán y a la unificación de Italia, países que ligados a nuevas alianzas alteraron la ecuación de las fuerzas predominantes en el viejo continente que arrasarían al mundo de comienzos del siglo XX. 
Esta revista forma parte del acervo de la Biblioteca Jurídica Virtual del Instituto de Investigaciones Jurídicas de la UNAM

En junio de 1914, los asesinato del archiduque Francisco Fernando de Austria y de su esposa, ocurridos en Sarajevo, incidentes de calado menor, encendieron las rivalidades de las casas reinantes, unidas por lazos de sangre y enemistadas sin cuartel por intereses de supremacía. Esa guerra, de extracción industria, se libró con nuevos medios y armamentos: el avión, los buques de guerra, los submarinos, las armas químicas, el tanque, la granada, el lanzallamas, y contagió a las colonias, llegó al Medio Oriente, hasta Japón. Y la gran novedad, Estados Unidos decidió jugar un rol mundial e hizo acto de presencia en los campos de batalla europeos hacia el fin del conflicto. El mundo se hacía uno al influjo de la ley de los cañones. Comparativamente, la Batalla de Austerlitz de los tres emperadores, Alejandro I, Francisco I y Napoleón se resolvió en un día, en tanto, la Primera Guerra Mundial duró cuatro años. Se dio por concluida la conflagración el día once, del mes once a la once de la mañana de 1918. Ni tardos ni perezosos, los vencedores iniciaron la Conferencia de Paz en París en enero de 1919. Las negociaciones fueron entre los victoriosos y las condiciones impuestas a Alemania en forma alguna le fueron consultadas, la mayor deferencia que se le dispensó fue una comunicación tajante y fría, error diplomático si se pretendía levantar una paz sólida y duradera y no provocar el resentimiento, el empobrecimiento y la frustración de la población, caldos de cultivo de la revancha fatal.

En el estudio comparativo de las épocas, Bremer, como buen diplomático, destaca el punto de la unilateralidad vengativa de la Conferencia de París, distinta a las negociaciones y acuerdos de Westfalia que le concedieron espacio político a los derrotados. La pavorosa destrucción y los millones de muertos que dejó la guerra despertaron en numerosos tratadistas y estadistas la inquietud de crear una institución que pudiera dirimir los antagonismos y darle oportunidad a la diplomacia. La propuesta señera fue la del presidente norteamericano Woodrow Wilson en sus célebres Catorce Puntos, enfilada a la creación de la Sociedad de las Naciones, parte del Tratado de Versalles que selló la imposición de la paz. El experimento del Pacto, de la también llamada Liga de las Naciones, prohibió parcialmente la guerra, no obstante, fue un intento esperanzador del nuevo orden.

En el periodo entreguerras Bremer alude al acuerdo de Locarno de 1925, una oportunidad para inventar la concordia entre los Estados europeos: Alemania, Francia, Bélgica, Gran Bretaña e Italia, que mereció la concesión del premio nobel de la Paz al francés Aristide Briand y al alemán 
Esta revista forma parte del acervo de la Biblioteca Jurídica Virtual del Instituto de Investigaciones Jurídicas de la UNAM

Gustav Stresemann. En ese vuelo optimista, se concluyó en 1928 el Tratado sobre la Prohibición de la Guerra, identificado con los apellidos de Aristide Briand, canciller de Francia, y Frank Kellogg, secretario de Estado norteamericano. En esta ocasión Kellogg fue galardonado con el Premio Nobel de la Paz. Suscrito por quince Estados, numerosos fueron los que se adhirieron con posterioridad al histórico instrumento. No eran los tiempos de la Belle Époque pero el horizonte se antojaba risueño y optimista... hasta que en 1933 el presidente de Alemania, Paul Von Hindenburg, llamó a Adolfo Hitler a formar gobierno. La Segunda Guerra Mundial estalló de manera fatídica. En lo tocante a la diplomacia durante el conflicto, hubo diferencias notables en comparación con la Primera Guerra Mundial, los principales líderes de los aliados, Roosevelt, Churchill y Stalin, sostuvieron reuniones cumbre (Moscú, Teherán, Dumbarton Oaks, Yalta) para planear la guerra en curso, delinear las zonas de influencia de la posguerra y crear una organización que sustituyera a la Sociedad de las Naciones que se había sumido en una especie de vida vegetativa.

Fue en las dos reuniones de Dumbarton Oaks, en Washington en 1944, en donde se elaboró el esquema y el tronco regulador principal de la futura institución, acorde con la premisa de los cuatro gendarmes de la posguerra, Estados Unidos, Reino Unido de la Gran Bretaña, Unión Soviética y República de China. Al igual que el presidente Woodrow Wilson, quien fungió como el animador de la Sociedad de las Naciones, el presidente Franklin D. Roosevelt, fue el impulsor notable de la nueva asociación de naciones, la que fue bautizada como Organización de la Naciones Unidas, nombre tomado de la Declaración de las Naciones Unidas del 1 de enero de 1942 que reunió a los Estados que estaban en guerra contra las potencias del Eje, en su origen el nombre identificó a los aliados e inclusive, en la Carta de la ONU se alude a los Estados ex enemigos.

La Conferencia de San Francisco se inició el 25 de abril de 1945, sin que hubiera acabado la guerra y a unos días de la muerte de Roosevelt. La Carta fue firmada el 26 de junio y entró en vigor el 24 de octubre del mismo año. Una coincidencia significativa: otro 24 de octubre pero tres siglos antes, en 1648, se firmaron los tratados de Münster y Osnabrück, que pusieron fin a la Guerra de los Treinta Años en Westfalia. Sabido es que el talón de Aquiles de la organización naciente fue la creación del Consejo de Seguridad con cinco miembros permanentes investidos con el derecho de veto, odiosa concesión, o más bien imposición, pero que en términos políticos 
Esta revista forma parte del acervo de la Biblioteca Jurídica Virtual del Instituto de Investigaciones Jurídicas de la UNAM

ha salvado a la humanidad de otra contienda mundial. En tiempos sobresaltados es preciso insistir en que la Carta de las Naciones Unidas cobija hoy a la casi totalidad de los Estados del mundo, es un instrumento humanista y pacifista, creado como órgano principal al Consejo Económico y Social, encargado de destinar la mayor parte del presupuesto de la ONU a sus tareas. En torno a la institución orbitan las organizaciones especializadas que atienden los más variados asuntos: finanzas, trabajo, alimentación, aviación, transporte marítimo, cultura y ciencia, etcétera, así como agencias particulares, como las de la infancia o los refugiados, y una estela inagotable de comisiones. El tejido normativo que se ha creado es espectacular, bien sea a través de convenciones o de instrumentos no vinculantes. Es una instancia fundamental para la diplomacia.

Concluye nuestro autor con un epílogo lúcido, una clarinada analítica sobre los problemas actuales que asolan a la humanidad: la crisis económica global de causas complejas, el aumento de actores medianos en los asuntos mundiales; las rivalidades de nuevo cuño derivadas de las religiones, de las oposiciones étnicas o del terrorismo internacional; violaciones a la Carta de las Naciones Unidas, como la guerra contra Irak en 2003; las migraciones desesperadas provenientes del Oriente Medio y del Norte de África que se suman a las tradicionales de origen económico. "Estamos en la mayor crisis humanitaria desde la Segunda Guerra Mundial”, sentencia Juan José. Menudo diagnóstico para un Siglo XXI en el que coexisten los impresionantes avances tecnológicos y una modernidad asombrosa con los rezagos de "los condenados de la tierra" (Frantz Fanon).

Esta reseña sigue la exposición de Juan José Bremer, quien en algunos puntos de la obra invita a aventurarse en variaciones sobre el gran tema que con maestría emprende. Dicen que hay tantos libros como lectores y, así, la lectura de Tiempos de Guerra y Paz despierta el interés de entablar un dialogo con el autor.

\section{Ricardo Méndez-Silva*}

\footnotetext{
* Investigador en el Instituto de Investigaciones Jurídicas de la UNAM.
} 